\title{
Reply: False positive result in study on hookah smoking and cancer in Kashmir: measuring risk of poor hygiene is not the same as measuring risk of inhaling water-filtered tobacco smoke all over the world
}

\author{
N A Dar ${ }^{\star}, 1,2, \mathrm{~F}$ Islami ${ }^{2,3}$ and P Boffetta ${ }^{*, 2,4}$ \\ ${ }^{1}$ Department of Biochemistry, University of Kashmir, Hazratbal, Srinagar 190006, India; ${ }^{2}$ Institute for Transitional Epidemiology, \\ Mount Sinai School of Medicine, New York, NY 10029, USA; ${ }^{3}$ Digestive Disease Research Center, Shariati Hospital, Tehran \\ University of Medical Sciences, Tehran 14117, Iran and ${ }^{4}$ International Prevention Research Institute, Lyon 69006, France
}

Sir,

We thank Chaouachi (2013) for his interest in our study (Dar et al, 2013). The first two paragraphs of his letter are on the potential role of changing the water of waterpipe basin. We did not find an association for the frequency of doing this practice and esophageal squamous cell carcinoma (ESCC) risk in adjusted models, as reported in our article. In a re-analysis of our data, including this frequency in adjusted models did not change the association between waterpipe smoking and ESCC risk (data not shown). Although we cannot exclude some association between frequency of changing water and ESCC risk based on a single study, our findings suggest that this association, if any, is not strong in this population, and therefore is unlikely to influence the association between waterpipe smoking and ESCC.

We agree with Chaouachi (2013) that cigarette-smoking machines may not be representative of exposure in waterpipe smokers. However, there is other evidence showing that waterpipe smokers are exposed to some harmful compounds present in tobacco, perhaps not as high levels as what have been reported with cigarette-smoking machines, but still at the levels significantly higher than non-smokers. Chaouachi (2013) states 'Admitting (absurd hypothesis) that such a 'protocol' were realistic, why did a German team found acrolein at levels 66 times lower
(6 times lower for formaldehyde and acetaldehyde) and benzo[a]pyrene 20 times lower than in the studies by the US-AUB cited by Dar et al and Maziak?'. This is correct, but Chaouachi (2013) does not state that the same German study detected five times higher formaldehyde levels during one waterpipe-smoking session when compared with one reference cigarette (Schubert et al, 2012), that the nicotine contents were 10 times higher and the levels of benzo[a]pyrene were 3 times higher in waterpipe smoke than in the reference cigarette, and that they found much higher nicotine and cotinine levels in the urine of waterpipe smokers than in urine of non-smokers (Schubert et al, 2011). While nicotine is not a carcinogen, each dose of nicotine delivered from tobacco smoke may be accompanied by established carcinogens (Hecht, 2003). Chaouachi (2013) also states referring to another study 'As for urinary concentrations of $\mathrm{PAH}$ metabolites, they were much less important in shisha smokers than in cigarette smokers by factors ranging from about 1.5-5'. Again, he does not mention that this study also reports substantial increase in plasma nicotine concentrations, comparable to cigarette smoking, in waterpipe smokers and significantly higher urinary excretion of NNAL and $\mathrm{PAH}$ biomarkers following waterpipe smoking, compared with non-smokers (Jacob et al, 2011). There are some other studies in humans that have shown similar or higher serum nicotine levels in 
waterpipe compared with cigarette smokers (Shafagoj et al, 2002; Cobb et al, 2011) and higher levels of some carcinogenic compounds in waterpipe smokers than in non-smokers (Radwan et al, 2013). Therefore, we do not believe that 'the similarity of biological consequences of waterpipe and cigarette smoking' is 'groundless', as Chaouachi (2013) has stated. The above findings also do not support the efficiency of water in filtering all harmful compounds in waterpipe smoke.

We believe that more experimental and epidemiological studies are required with regard to health effects of waterpipe smoking. However, although their number is limited, all previous epidemiological studies on waterpipe smoking and ESCC risk have suggested a positive association (Nasrollahzadeh et al, 2008; Khan et al, 2011; Malik et al, 2011). The above biomarker studies may provide further support for this association and make it plausible. Chaouachi (2013) fails in providing any solid evidence against the association between waterpipe smoking and ESCC risk. We agree that speculation is an important part of hypothesis making, but concluding that results of a study (which is also supported by all available evidence) are false-positive needs stronger evidence than speculations.

Chaouachi (2013) also states 'Smoking behaviour of a Kashmiri hookah is completely different from those of the fashionable shisha used these days in Washington or London, both Dar et al and Maziak extrapolate false positive findings to the whole world'. We wonder if he is aware of any study that have compared the settings of waterpipe smoking and found 'completely different' exposures to tobacco compounds. If not, we are not sure how Chaouachi (2013) has reached to this strong conclusion. We agree that variation in smoking behaviour and composition of smoke in different waterpipe-smoking settings are very likely. In fact, such variation may exist with chewing tobacco products, because in various geographical areas tobacco may be mixed with various other ingredients and people may have different chewing behaviour. However, many chewing tobacco products are known risk factors for oesophageal cancer (Secretan et al, 2009). Variation in a smaller scale may also exist with cigarette smoking (variation in composition by cultivation area of tobacco or processing method; having or not having filters; the depth of inhalation of cigarette smoke; and so forth). Nevertheless, cigarette smoking is considered as a risk factor for ESCC (Secretan et al, 2009). The current evidence is strongly suggestive of an association between high exposure to tobacco compounds in various settings and ESCC risk, even if tobacco is flavoured or mixed with other compounds or used in different ways. This may further support the association between waterpipe smoking and ESCC.

Overall, although more studies on health effects of waterpipe smoking are warranted, the current evidence may indicate that the tobacco control programs should include tobacco products other than cigarette more strictly. Because of the latency period between exposure to tobacco smoke and development of cancer, the incidence of cigarette smoking-related cancers peaked several decades after this habit became popular. As a shift from cigarette smoking to other tobacco products has been reported in many populations (Warren et al, 2009; Bhattacharyya, 2012), such prevention may alleviate a potential surge in the incidence of cancers related to tobacco products other than cigarette in future.

Finally, we appreciate Chaouachi's (2013) interest in health effects of waterpipe smoking, which is evident from his large number of published Letters to the Editors following publication of original papers by other researchers. However, we believe it will be more informative for the readers if he cites the results of previous studies unselectively and support his conclusions by results of actual studies rather than speculations.

\section{REFERENCES}

Bhattacharyya N (2012) Trends in the use of smokeless tobacco in United States, 2000-2010. Laryngoscope 122: 2175-2178.

Chaouachi K (2013) False-positive result in study on hookah smoking and cancer in Kashmir. Measuring risk of poor hygiene is not the same as measuring risk of inhaling water filtered tobacco smoke all over the world. Br J Cancer 108(6): 1389-1390.

Cobb CO, Shihadeh A, Weaver MF, Eissenberg T (2011) Waterpipe tobacco smoking and cigarette smoking: a direct comparison of toxicant exposure and subjective effects. Nicotine Tob Res 13: 78-87.

Dar NA, Bhat GA, Shah IA, Iqbal B, Makhdoomi MA, Nisar I, Rafiq R, Iqbal ST, Bhat AB, Nabi S, Shah SA, Shafi R, Masood A, Lone MM, Zargar SA, Najar MS, Islami F, Boffetta P (2012) Hookah smoking, nass chewing, and oesophageal squamous cell carcinoma in Kashmir, India. Br J Cancer 107(9): 1618-1623.

Hecht SS (2003) Tobacco carcinogens, their biomarkers and tobacco-induced cancer. Nat Rev Cancer 3: 733-744.

Jacob III P, Abu Raddaha AH, Dempsey D, Havel C, Peng M, Yu L, Benowitz NL (2011) Nicotine, carbon monoxide, and carcinogen exposure after a single use of a water pipe. Cancer Epidemiol Biomarkers Prev 20: $2345-2353$.

Khan NA, Teli MA, Mohib-Ul HM, Bhat GM, Lone MM, Afroz F (2011) A survey of risk factors in carcinoma esophagus in the valley of Kashmir, Northern India. J Cancer Res Ther 7: 15-18.

Malik MA, Sharma KL, Zargar SA, Mittal B (2011) Association of matrix metalloproteinase-7 (-181A4G) polymorphism with risk of esophageal squamous cell carcinoma in Kashmir Valley. Saudi J Gastroenterol 17: 301-306.

Nasrollahzadeh D, Kamangar F, Aghcheli K, Sotoudeh M, Islami F, Abnet CC, Shakeri R, Pourshams A, Marjani HA, Nouraie M, Khatibian M, Semnani S, Ye W, Boffetta P, Dawsey SM, Malekzadeh R (2008) Opium, tobacco, and alcohol use in relation to oesophageal squamous cell carcinoma in a high-risk area of Iran. Br J Cancer 98: 1857-1863.

Radwan G, Hecht SS, Carmella SG, Loffredo CA (2013) Tobacco-specific nitrosamine exposures in smokers and nonsmokers exposed to cigarette or waterpipe tobacco smoke. Nicotine Tob Res 15: 130-138.

Schubert J, Hahn J, Dettbarn G, Seidel A, Luch A, Schulz TG (2011) Mainstream smoke of the waterpipe: does this environmental matrix reveal as significant source of toxic compounds? Toxicol Lett 205: 279-284.

Schubert J, Heinke V, Bewersdorff J, Luch A, Schulz TG (2012) Waterpipe smoking: the role of humectants in the release of toxic carbonyls. Arch Toxicol 86: 1309-1316.

Secretan B, Straif K, Baan R, Grosse Y, El Ghissassi F, Bouvard V, Benbrahim-Tallaa L, Guha N, Freeman C, Galichet L, Cogliano V. WHO International Agency for Research on Cancer Monograph Working Group (2009) A review of human carcinogens-Part E: tobacco, areca nut, alcohol, coal smoke, and salted fish. Lancet Oncol 10: 1033-1034.

Shafagoj YA, Mohammed FI, Hadidi KA (2002) Hubble-bubble (water pipe) smoking: levels of nicotine and cotinine in plasma, saliva and urine. Int $J$ Clin Pharmacol Ther 40: 249-255.

Warren CW, Lea V, Lee J, Jones NR, Asma S, McKenna M (2009) Change in tobacco use among 13-15 year olds between 1999 and 2008: findings from the Global Youth Tobacco Survey. Glob Health Promot 16(2 Suppl): $38-90$. 